\title{
Semiosis entre palabras e imágenes en Twitter. ¿Cómo construyen significados los candidatos presidenciales de las elecciones 2017 de Chile?'
}

\author{
Liliana Cecilia Vásquez-Rocca' \\ https://orcid.org/0000-0002-2445-3253 \\ I - Facultad de Educación y Ciencias Sociales \\ Viña del Mar, Chile
}

Resumen: En la última década, con la explosión del uso de las redes sociales (Facebook, Twitter, Instagram), diferentes actores sociales han comenzado a utilizarlas. En particular, Twitter ha tenido un rol protagónico en las campañas presidenciales en el mundo y Chile no ha sido la excepción. En cuanto a la investigación sobre Twitter en el ámbito del análisis de discurso, estas se concentran, principalmente, en tres líneas: interacción, argumentación y uso de hashtag, sin embargo, no existen estudios que se interesen por las relaciones de significados que se producen entre imágenes y palabras (intersemiosis) en un tweet. Por ello, se busca describir las relaciones intersemióticas entre palabras e imágenes estáticas que se utilizan en los tweets de los 8 candidatos presidenciales de las elecciones 2017 de Chile. La metodología considera un enfoque cualitativo. Los resultados muestran que las relaciones que prevalen son: elaboración y evidencia, las que estarían asociadas con la medición de interacción que obtiene cada candidato.

Palabras claves: Twitter; multimodalidad; Teoría de la Estructura Retórica (RST); participación política.

Abstract: Semiosis between words and images on Twitter. How are meanings built by the presidential candidates of the $\mathbf{2 0 1 7}$ elections in Chile? - In the last decade, with the explosion of the use of social networks (Facebook, Twitter, Instagram), different social actors have begun to use them. In particular, Twitter has played a leading role in presidential campaigns around the world and Chile has not been the exception. Regarding the research on Twitter in the field of discourse analysis, these are mainly concentrated on three lines: interaction, argumentation

1 Este artículo se enmarca dentro del proyecto Jorge Millas DI-28-18JM, Universidad Andres Bello, Dirección de Investigación, Departamento de Humanidades. 
and use of the hashtag, however, there are no studies that are interested in the relationships of meanings that are produced between images and words (intersemiosis) in a tweet. Therefore, we seek to describe the intersemiotic relations between words and static images that are used in the tweets of the 8 candidates of the 2017 presidential elections in Chile. The methodology considers a qualitative approach. The results showed that the prevailing relations are: Elaboration and Evidence, the ones that will be associated with the measurement of interaction that every candidate obtained.

Keywords: Twitter; multimodality; RST; political participation.

\section{Introducción}

A fines del año 2017 la red social Twitter hizo un cambio relevante en su funcionamiento: extendió a 280 caracteres un tweet a cerca de 320 millones de usuarios que mantiene actualmente. Una de las razones esgrimidas por la empresa para adoptar esta medida fue la diferencia que presentan diferentes idiomas para expresarse, por ejemplo, en algunas lenguas la concisión requeriría de menos caracteres que en otras. Este cambio en Twitter se produjo en el momento en que la campaña electoral presidencial 2017 en Chile estaba en un minuto álgido, con una fragmentada competencia entre 8 candidatos.

La elección presidencial 2017 en Chile fue muy diferente, puesto que tuvo dos características que la distinguieron. Por un lado, cambios legales y, por otro, el contexto social mediático en asociación a la corrupción política. En este escenario, el 20 de octubre de 2017 comenzó la franja electoral que se difunde por la televisión abierta, transmitida obligatoriamente por todos los canales en cadena nacional (CHILE, 1988). Si bien se trata de uno de los principales instrumentos de comunicación política en Chile, no es el único que utilizaron los presidenciables. Otra de las herramientas escogidas fue Twitter, ya que es una de las redes sociales más consultada y utilizada para informarse (NEWMAN et al., 2017).

Twitter ha tomada relevancia en diversas elecciones presidenciales en el mundo (SURAY, 2016; ALONSO-MUÑOZ; MIQUEL-SEGARRA; CASERO-RIPOLLÉS, 2016), principalmente por convertirse en una plataforma que: permite la comunicación horizontal con el ciudadano, es utilizada por la clase política y también entre los periodistas (ORIHUELA, 2012; MANCERA-RUEDA, 2014), aporta imagen de modernidad (CALDEVILLA DOMÍNQUEZ, 2009), por lo general, quienes utilizan Twitter son líderes de opinión (RODRÍGUEZ ANDRÉS; UCEDA UREÑA, 2011) y humaniza a los políticos y aumenta la empatía hacia ellos.

Ahora bien, en el ámbito del periodismo y de las comunicaciones, los estudios de Twitter relevan su uso comunicacional, la influencia de lideres de opinión, el análisis de big data. En cambio, en el contexto del análisis del discurso, son menos los estudios que se focalizan en Twitter, concentrándose, principalmente, en el análisis de la argumentación (SURAY, 2016), del uso de hashtags (ZAPPAVIGNA, 2011) y de las interacciones en esta 
red social (HONEYCUTT; HERRING, 2009). Sin embargo, al menos para el español, no existen estudios que investiguen las relaciones de significados que se producen entre la imagen y el cotexto verbal, es decir, la intersemiosis (LIU; O'HALLORAN, 2009) de un tweet en el ámbito político.

Así, esta investigación busca describir las relaciones intersemióticas que se producen entre la imagen estática y el cotexto verbal que twitearon los candidatos presidenciales de las elecciones de Chile 2017.

En lo que sigue el artículo se ordena de la siguiente forma, en primer lugar, se presenta el contexto político social de las elecciones en Chile, luego, el estudio de Twitter, la perspectiva del estudio multimodal y se continúa con un breve recuento de lo que es la Teoría de la Estructura Retórica (RST, por sus siglas en inglés). Posteriormente, se presenta la metodología y a continuación los resultados y su discusión. Finalmente, se exponen las conclusiones y limitaciones del estudio.

\section{Contexto social y político de las elecciones 2017 en Chile}

La situación política y social que enmarca las elecciones presidenciales 2017 fue diferente a las anteriores, principalmente por dos razones. En primer lugar, cambios en la normativa legal, que se refiere al inicio del sistema de elección proporcional, que buscó dar mayor representatividad a los diferentes partidos políticos en el Congreso, eliminando el sistema binominal. También, se definió la restricción de los gastos electorales y una mayor transparencia en el financiamiento, ya que sólo se pueden ocupar recursos provenientes de aportes públicos de anticipos o reembolsos, de personas naturales y de partidos políticos. No así de empresa. Asimismo, se incorporó una cuota en las listas parlamentarias, lo que implicó que cada conglomerado político llevara al menos un 40 \% de mujeres en sus listas (ARELLANO; FERNÁNDEZ, 2017). Estos cambios legales hicieron que el escenario político fuera poco previsible.

En segundo lugar, se vive un contexto social mediático particular, puesto que, dados los diferentes casos de corrupción que dan cuenta de los vínculos entre la política y las empresas en Chile (SOLA-MORALES; GALLARDO, 2016), los diversos conglomerados políticos están siendo vigilados socialmente con mayor insistencia, lo que produjo una disminución del gasto electoral de todos los candidatos y, consecuentemente, menor cantidad de publicidad en medios de comunicación y vía pública (CHILE, 2003).

En el escenario antes descrito, se observó la necesidad de que los candidatos políticos intensificaran sus esfuerzos para comunicar sus propuestas a través de diversos métodos, no sólo los tradicionales, como la franja televisiva o la publicidad en la vía pública, sino a través de plataformas como Facebook o Twitter. Estudios de reciente data dan cuenta que el uso de diferentes herramientas digitales durante periodos de campaña se han tornado más frecuente y, a la vez, diversos (CHADWICK, 2013; STROMER-GALLEY, 2014). 


\section{Twitter como herramienta de comunicación política}

Actualmente Twitter cuenta con más de 320 millones de usuarios en el que más del 80\% lo utiliza a través de un móvil (PINGDOM, 2015). Según una encuesta desarrollada por la Reuters Institute la segunda motivación principal con que se ocupa Twitter es para estar informado y debatir (NEWMAN et al., 2017). Así, se ha convertido en la red social más utilizada para informarse sobre lo que sucede en sus entornos, incluso para movilizar diversas causas sociales. Un tweet puede provocar un efecto dominó, ya que lo que se publica en Twitter se transmita muy rápidamente, en tiempo real (CONGOSTO; FERNÁNDEZ; MORO, 2011). Pero para que esto se produzca, es decir, para obtener atención y participación regular de los seguidores es necesario aportar valor (ORIHUELA, 2011). Al respecto, Golbeck, Grimes y Rogers (2010) y Jungherr (2016) señalan que diversos actores sociales, principalmente políticos, le otorgan ciertas funciones a Twitter. En este sentido, existirían cuatro principales: reproducir la información sobre sus actividades, entregar sus propias declaraciones frente a temas de contingencia social, compartir links de interés en diversos ámbitos y, por último, apoyar la obtención de recursos para sus campañas.

En las redes sociales, las lógicas no son las mismas que en los medios tradicionales (JERVIS, 2015; RAMONET, 2011). Las audiencias son diferentes, no son pasivas ni desinformadas, por el contrario, quieren participar, y por lo tanto, se esperaría que los políticos apelaran e interactuaran con sus audiencias cautivas. Asimismo, sería deseable que los diferentes actores sociales usaran esta plataforma para medir la opinión pública (ORIHUELA, 2011).

Otro aspecto relevante de Twitter es la posibilidad de interacción. Diversos estudios concluyen que la participación de las audiencias de manera activa entrega mayores beneficios para los conglomerados políticos. Sin embargo, los diversos candidatos que usan las redes en sus campañas no obtienen beneficios de esta característica (GRANT; MOON; GRANT, 2010), por el contrario, la comunicación con sus seguidos es poco habitual (RODRÍGUEZ ANDRÉS; UCEDA UREÑA, 2011). En relación a la interacción con sus seguidores, hoy en día, existe un consenso en medir este criterio con la tasa de engagement (CALVO-RUBIO, 2017).

\section{Análisis multimodal en el siglo XXI}

El análisis multimodal, desde la perspectiva discursiva, implica comprender que la construcción de significados no se realiza solo por medios de palabras, sino que existen otros elementos que intervienen. Hodge y Kress (1988) proponen dos ideas fundamentales para comprender la multimodalidad. Primero que la creación de significado está dada por la disponibilidad de sistemas que una comunidad posee y ha desarrollado históricamente. La segunda idea que proponen los autores es que la construcción de significados está dada por relaciones de poder y solidaridad, al querer, por un lado, distinguirse y, por otro lado, pertenecer a determinados grupos sociales. En este sentido, la elección de los medios y modos (KRESS, 2005) no es al azar, tiene un propósito que está detrás. 
Estas premisas son las que siguen Kress y van Leeuwen (2001) para sustentar el desarrollo del estudio de la multimodalidad. De esta forma, los estudios empíricos en esta línea han aumentado de manera exponencial en todo el mundo (TABOADA; HABEL, 2013; JOVANOVIC; VAN LEEUWEN, 2018).

Cabe precisar, entonces, que la multimodalidad se comprende como la construcción de significado de un texto por medio de diversos recursos semióticos. Ya no son las palabras solo las que construyen la idea, sino que en conjunto con las imágenes otorgan sentido a lo que se quiere señalar. Como indica Barthes (2014) el sistema verbal ancla las imágenes, por tanto, conduce al lector a través de los posibles significados de la imagen y, en cierta forma, lo obliga a "evitar unos y recibir otros" (BARTHES, 2014, p.40), por lo tanto, la relación entre imágenes y palabras no es una selección al azar.

\section{La RST y su contribución al análisis de la intersemiosis}

La RST tiene su origen en la generación automática de textos y ofrece una explicación a la coherencia de estos, en la que cada parte tiene un papel evidente y distintivo (TABOADA; MANN, 2006). Actualmente se han elaborado más de 30 relaciones semánticas (MANN; TABOADA, 2010) que están destinadas originalmente a describir vínculos entre unidades de palabras, sin embargo, en los últimos 5 años la RST han sido aplicadas a relaciones entre palabras e imágenes, palabras y gráficos, entre otros. En específico, las relaciones semánticas se agrupan en dos ámbitos: multinuclear y núcleo-satélite. En el primero, al menos dos núcleos están conectados al mismo nivel, sin embargo, no se produce una dependencia entre los elementos. En el caso de las relaciones núcleo-satélite, se puede observar una relación de dependencia en que un elemento no se puede entender sin el otro. La definición de algunas de las relaciones se presentan en la Tabla 1.

\begin{tabular}{|c|c|c|c|}
\hline $\begin{array}{l}\text { Nombre de la } \\
\text { Relación }\end{array}$ & $\begin{array}{l}\text { Condiciones en Satélite (S) } \\
\text { o Núcleo }(\mathrm{N}) \text {, individualmente }\end{array}$ & $\begin{array}{c}\text { Condiciones en N (Núcleo) } \\
+\mathrm{S} \text { (Satélite) }\end{array}$ & Intención de Autor (A) \\
\hline Elaboración & Ninguna & $\begin{array}{l}\text { S presenta detalles sobre la situación o } \\
\text { al-gún elemento en } \mathrm{N} \text { o accesible en } \mathrm{N} \\
\text { me-diante una de las inferencias que se } \\
\text { presen-tan a continuación. En la lista, N se } \\
\text { refiere a la primera parte del par, y S } \\
\text { a la segunda: } \\
\text { - conjunto " miembro } \\
\text { - abstracto " ejemplo } \\
\text { - todo " parte } \\
\text { - proceso " paso } \\
\text { - objeto " atributo } \\
\text { - generalización" específico }\end{array}$ & $\begin{array}{l}\text { L reconoce que la } \\
\text { situación presen-tada } \\
\text { en S propor-ciona } \\
\text { detalles para N. L } \\
\text { identifica el elemento } \\
\text { para el que se han } \\
\text { pro-porcionado los } \\
\text { detalles }\end{array}$ \\
\hline Evidencia & $\begin{array}{l}\text { En } N \text { : L podría no creer } \mathrm{N} \text { de } \\
\text { manera satisfactoria para } A \text { en } \\
\text { S: L acepta } S \text { o lo encuentra } \\
\text { creíble }\end{array}$ & $\begin{array}{l}\text { La comprensión de } S \text { por parte de } \mathrm{L} \\
\text { aumenta la aceptación de } \mathrm{N} \text { por parte de } \mathrm{L}\end{array}$ & $\begin{array}{l}\text { Aumenta la } \\
\text { aceptación de } N \\
\text { por parte de } \mathrm{L}\end{array}$ \\
\hline
\end{tabular}

Tab. 1. Definición de 2 relaciones tomadas de la RST (MANN; TABOADA, 2010) 
En cuanto al análisis, de acuerdo a Mann y Thompson (1988), la exploración en los textos busca representar juicios plausibles para el analista. De esta manera, el procedimiento consiste en dividir en unidades el texto. Cabe precisar que el tamaño de la unidad es arbitrario; podría ser una oración, un grupo de oraciones, entre otros. Sin embargo, el principio que rige esta división es que debe representar lo que el autor del texto quiere vincular.

Un ejemplo del procedimiento de análisis se presenta en la Figura 1. En este caso, el núcleo es la imagen (noticia de El Mercurio), ya que el cotexto verbal (palabras) no puede ser comprendido por el lector sin ella. En el cotexto el emisor, en este caso Marco Enríquez Ominami, realiza un juicio sobre otro candidato (Sebastián Piñera). El cotexto verbal (satélite) se refiere a la imagen de la noticia (núcleo), específicamente al grado de actitud positiva que tiene el autor del tweet respecto de la noticia, es decir, Marco Enríquez Ominami está de acuerdo con lo que se publica en la noticia y lo reafirma en el cotexto verbal (palabras). Esto hace que quien lea el tweet pueda apreciar en el cotexto verbal el respaldo hacia el núcleo (imagen de noticia) y pueda reconocer que el emisor (Marco Enríquez Ominami) le asigna valor, en este caso, de ayudar a demostrar que otro candidato es mentiroso.

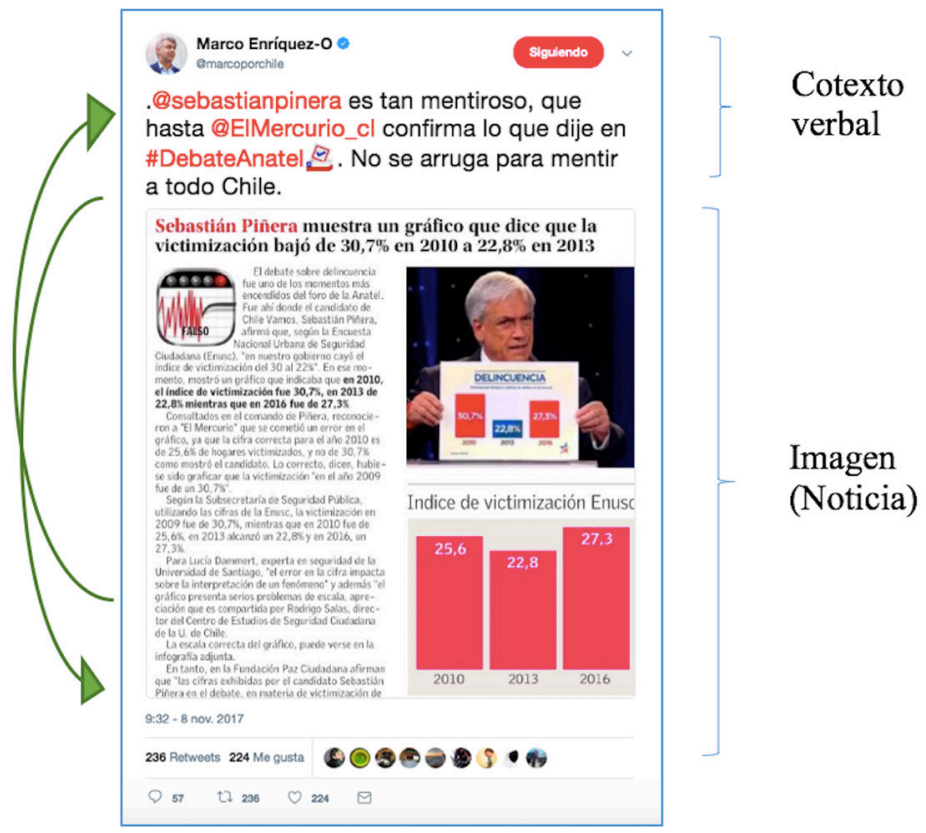

\begin{tabular}{|c|c|}
\hline Fecha tweet & 8 de noviembre de 2017, 9:32 a.m. \\
\hline Candidato & Marco Enríquez Ominami \\
\hline Relación intersemiótica (RST): & Evaluación \\
\hline
\end{tabular}

Fig. 1. Ejemplo de relación intersemiótica de evaluación 


\section{Marco metodológico}

En el siguiente apartado se expone el marco metodológico. En este sentido, se trata de una investigación de tipo cualitativa, de alcance descriptivo, con diseño no experimental, transeccional (CRESWELL, 1994; HERNÁNDEZ; FERNÁNDEZ; BAPTISTA, 2010). El objetivo del estudio es describir las relaciones que se producen entre la imagen estática y el cotexto verbal que twitearon los 8 candidatos presidenciales de las elecciones de Chile 2017 (ver Tabla 2) durante la emisión de la franja de la primera vuelta presidencial.

\begin{tabular}{|c|c|}
\hline Candidatos & Pacto que representan \\
\hline Eduardo Artés & Unión Patriótica \\
\hline Beatriz Sánchez & Frente Amplio \\
\hline Sebastián Piñera & Chile Vamos \\
\hline Marco Enríquez Ominami & Partido Progresista \\
\hline Carolina Goic & Democracia Cristiana \\
\hline Alejandro Navarro & Partido País \\
\hline José Antonio Kast & Independiente (derecha) \\
\hline Alejandro Guillier & Independiente (centro-izquierda) \\
\hline
\end{tabular}

Tab. 2. Candidatos presidenciales Chile 2017.

A partir de lo anterior, el corpus está constituido por todos los tweets emitidos por los candidatos presidenciales de la primera vuelta durante la emisión de la franja electoral, esto es, entre el 20 de octubre y 19 de noviembre de 2017. No se consideran los retweets de los candidatos presidenciales. Luego de definidos los criterios de selección, se obtuvo como resultado el corpus candidatos-2018 que considera un total de 178.616 tweets de los cuales 309 tweets utilizaban imagen estática y cotexto, lo que se convirtió en el subcorpus denominado intersemiosis-2018.

El análisis se realizó en tres etapas. En la primera se registraron las frecuencias relativas de la totalidad del Corpus en cuanto a: número de tweets, seguidores, personas o instituciones a quienes siguen y botón Me gusta. Con estos datos se obtuvo la tasa de engagement. En la segunda etapa, se analizó el 33\% del corpus en que se obtuvieron las relaciones intersemióticas más prototípicas de este. Luego de ellos, se solicitó a tres expertos en lingüística que validaran el análisis. Recibidos sus comentarios se ajustó el análisis y se prosiguió con la totalidad del subcorpus (33\%). La validación del estudio obtuvo un porcentaje de acuerdo de $83 \%$ y un coeficiente de Kappa de 0,70 lo que según Landis y Kock (1977) es un acuerdo considerable².

2 Cabe señalar que para el cálculo del coeficiente Kappa de Fliess se utilizó la aplicación Online Kappa Calculator a la que es posible acceder desde el sitio web: http://justusrandolph.net/kappa/. 


\section{Resultados y discusión}

En este apartado se presentan los resultados de la siguiente forma. En primer lugar, se exponen datos generales de uso de Twitter de todos los candidatos incluyendo la totalidad del corpus candidatos-2018. A continuación, se presentan los datos obtenidos en cuanto al tipo de relación semántica presentada en los tweets de los postulantes al gobierno de Chile: el subcorpus intersemiosis-2018.

En términos generales la mayoría de los candidatos se unió a Twitter antes de presentarse como candidato presidencial. Como se puede observar en la Figura 2, en febrero de 2008 se incorporaron a esta red social Sebastián Piñera y Carolina Goic. Un año después le siguen Marco Enríquez Ominami, Alejandro Navarro y Beatriz Sánchez.

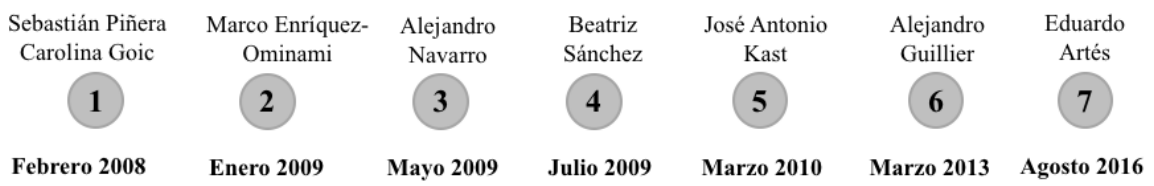

Fig. 2. Línea de tiempo de candidatos en la Red social Twitter

Lo anterior muestra que los candidatos, como ha ocurrido en otros procesos electorales (BARBERÁ; RIVERO, 2014; SURAY, 2016; ALONSO-MUÑOZ; MIQUELSEGARRA; CASERO-RIPOLLÉS, 2016), no crean sus cuentas sólo para esta elección, sino que la utilizan para tener una presencia mediática en la discusión pública en Chile, salvo el caso de Eduardo Artés, quien creó su cuenta tan solo un año antes de las elecciones.

Ahora bien, respecto de la actividad de la cuenta de cada candidato durante la franja presidencial, de acuerdo al Gráfico 1, destacan dos presidenciables, por un lado, Enríquez Ominami (68.700) y Sánchez (61.500) con la mayor cantidad de tweets emitidos, lo que podría significar una mayor comprensión del rol actual de las redes sociales (JERVIS, 2015; RAMONET, 2011), sin embargo, es necesario observar cuál es el uso específico que realizan los candidatos.

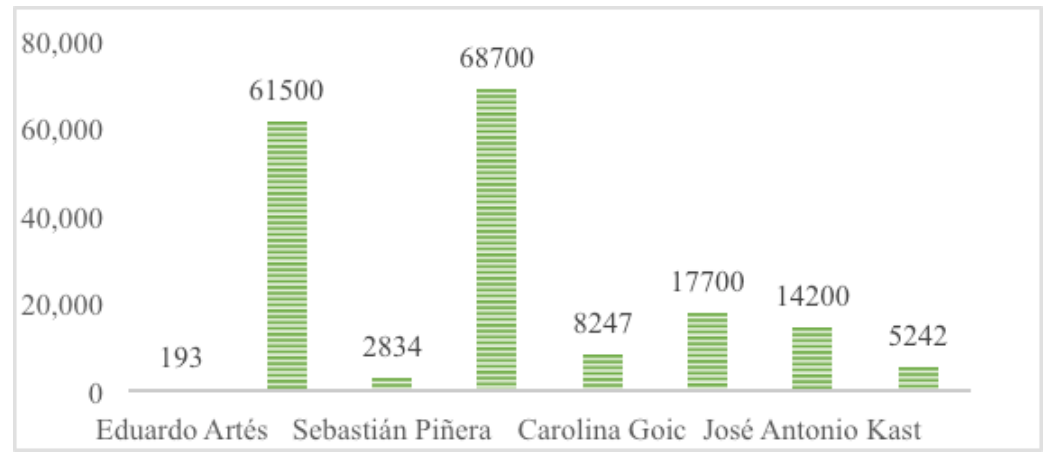

Gráf. 1. Número de tweets emitidos por los candidatos durante franja. 
Respecto del número de seguidores, de acuerdo al Gráfico 2, uno de los candidatos que se aleja considerablemente del resto es Piñera con 1.980.000 seguidores. Sin embargo, se determinó que sólo el 51\% de los seguidores de Piñera pudieron ser confirmados como tales (TWITTER..., 2017). Aún así la cantidad de seguidores sigue siendo más alta que el resto de candidatos. Esto podría explicarse por la mayor presencia mediática que ha tenido Piñera en la política chilena históricamente, siendo incluso Presidente de la república durante el periodo 2010-2014. Luego, se ubica Enríquez Ominani quien también se distancia del resto de los candidatos y también ha sido postulante a la presidencia en dos ocasiones anteriores.

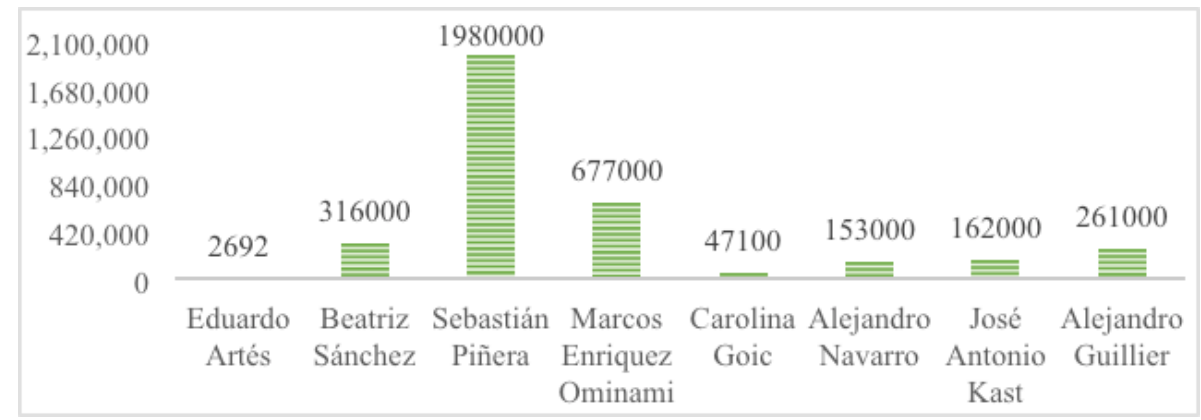

Gráf. 2. Número de seguidores de cada candidatos al finalizar la franja.

Ahora bien, respecto de las personas o instituciones que siguen los candidatos, tal como se aprecia en el Gráfico 3, Ilama la atención el candidato Kast que sigue a más de 73 mil cuentas, luego se encuentra Ominami y Piñera. Interesante es observar este dato a la luz de lo que plantean los investigadores en cuanto a la posibilidad que brinda Twitter de interactuar con otros seguidos de manera más directa (RODRÍGUEZ ANDRÉS; UCEDA UREÑA, 2011). Al revisar los resultados, sólo 3 candidatos de los 8 parecieran potenciar su vínculo con seguidores a través de la acción de seguir a una gran cantidad de cuentas, ya que este hecho podría evidenciar una voluntad de considerar el contacto con los usuarios y consecuentemente una mayor horizontalidad de la comunicación. El resto podría estar entendiendo la plataforma como una réplica de lo que se produce en los medios tradicionales y, por lo tanto, el interés sería de la audiencia por seguirlos y no a la inversa (GOLBECK; GRIMES; ROGERS, 2010; JUNGHERR, 2016). 


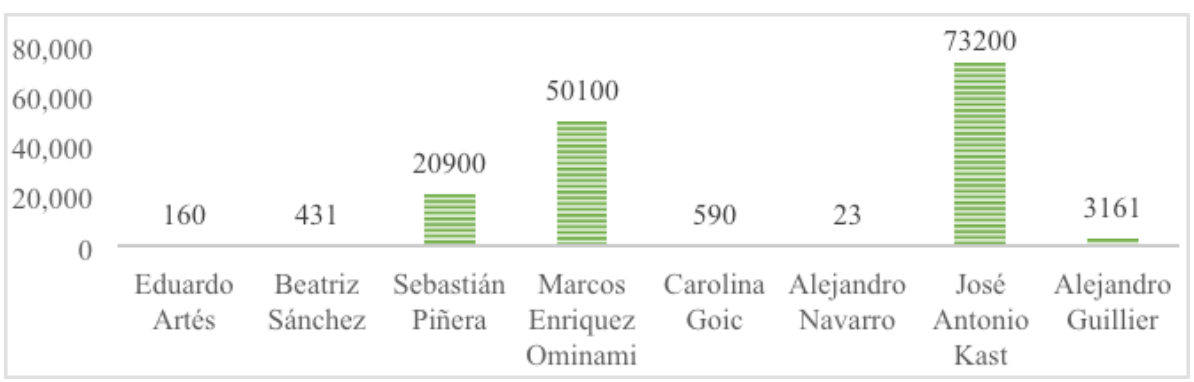

Gráf. 3. Número de personas o instituciones que siguen los diferentes candidatos

El botón Me gusta también resulta ser una medición, en cierta medida, del grado de interacción que los usuarios de Twitter tienen con sus seguidores y de su acción orientada a involucrarse con quien sigue la cuenta. Tal como se aprecia en el Gráfico 4, lideran los datos Enríquez Ominami y Goic.

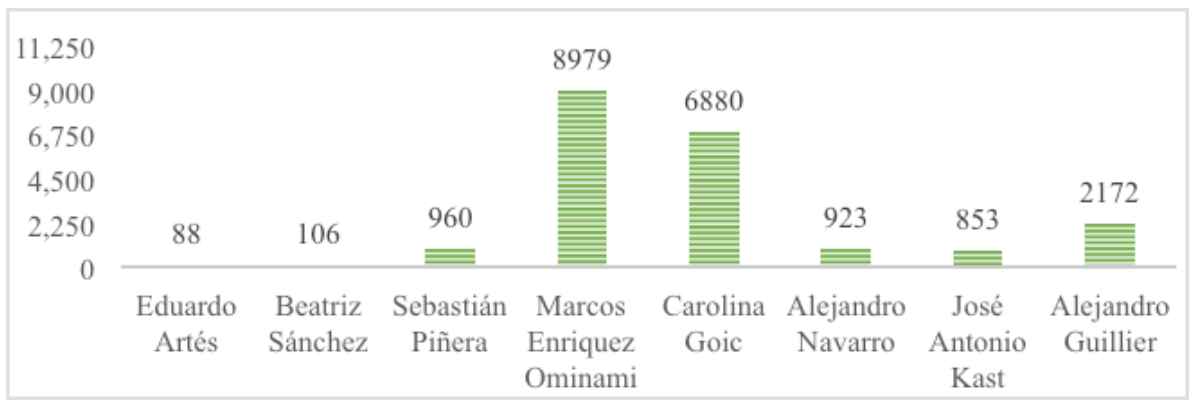

Gráf. 4. Número de Me gusta de tweets de candidatos presidenciales

Una medición que genera consenso en la investigación en Twitter es la tasa de engagement, la cual mide el grado de interacción de una determinada cuenta. En este estudio se sigue una adaptación de la tasa de engagement confeccionada por Calvo-Rubio (2017). La fórmula consiste en la división de la cantidad de seguidores por la suma de: retweets, Me gusta y comentarios que tiene la cuenta y luego ese resultado se divide por 100 obteniendo el porcentaje de engagement de una cuenta. Mientras más alto el resultado más es la interacción que la cuenta tiene con sus seguidores. En este caso, para el análisis de los candidatos presidenciales de Chile 2017 al término de la franja electoral, los resultados se muestran en la Tabla 3. 


\begin{tabular}{|c|c|c|c|c|c|}
\hline Candidatos & Seguidores & Retweet & Me gusta & Comentarios & Engagement \\
\hline Eduardo Artés & 2.692 & 0 & 88 & 0 & $\mathbf{3 , 3} \%$ \\
\hline Beatriz Sánchez & 316.000 & 4.484 & 106 & 951 & $\mathbf{1 , 8} \%$ \\
\hline Sebastián Piñera & 1.980 .000 & 9.335 & 960 & 4.873 & $\mathbf{0 , 8} \%$ \\
\hline Marco Enríquez Ominami & 677.000 & 6.887 & 8.979 & 3.092 & $\mathbf{2 , 8} \%$ \\
\hline Carolina Goic & 47.100 & 2.840 & 6.880 & 480 & $\mathbf{2 1 , 7} \%$ \\
\hline Alejandro Navarro & 153.000 & 4.459 & 923 & 1.565 & $\mathbf{4 , 5} \%$ \\
\hline José Antonio Kast & 162.000 & 13.805 & 853 & 3.542 & $\mathbf{1 1 , 2} \%$ \\
\hline Alejandro Guillier & 261.000 & 13.867 & 2.172 & 4.060 & $\mathbf{7 , 7} \%$ \\
\hline
\end{tabular}

Tab. 3. Tasa de engagement

Como se puede observar, el candidato que más interacción tiene con sus usuarios es Goic $(21,7 \%)$, que pese a tener un bajo número de seguidores, logra utilizar la red social para comunicarse con ellos y por tanto, evidencia su intención de interactuar. Es seguida por Kast $(11,2 \%)$. Los restantes 6 candidatos tienen bajo el 10\%. Estos datos muestran que no se utiliza el potencial interactivo de Twitter y más bien su función es de amplificador de sus mensajes lo que también se ha verificado en otros estudios (GOLBECK; GRIMES; ROGERS, 2010; JUNGHERR, 2016).

\section{Resultados de la Intersemiosis}

Con respecto al uso que se hace de imágenes estáticas y su respectivo cotexto verbal, en una mirada global se puede observar que principalmente los candidatos privilegian dos tipos de relaciones: elaboración (48\%) y evidencia (33\%), como se aprecia en el Gráfico 5.

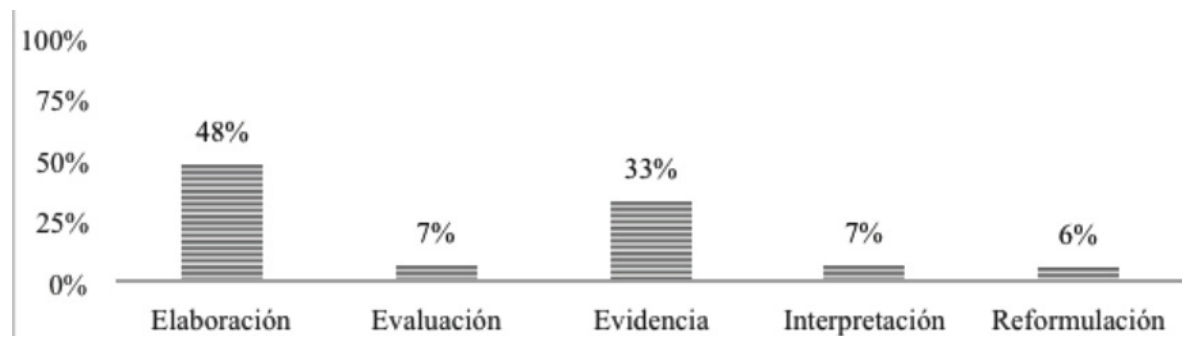

Gráf. 5. Relaciones semánticas entre palabras e imágenes

Ahora bien, si se observa el desglose del uso de las relaciones intersemióticas entre candidatos, como se expone en el Gráfico 6, se presentan interesantes variaciones que están en concordancia con la tasa de engagement. A la luz de los datos y correspondencia con las relaciones intersemióticas se observa un fuerte vínculo entre el uso de relaciones 
de interpretación y evidencia con un mayor porcentaje de interacción dado por la tasa de engagement en los candidatos Goic, Navarro y Kast.

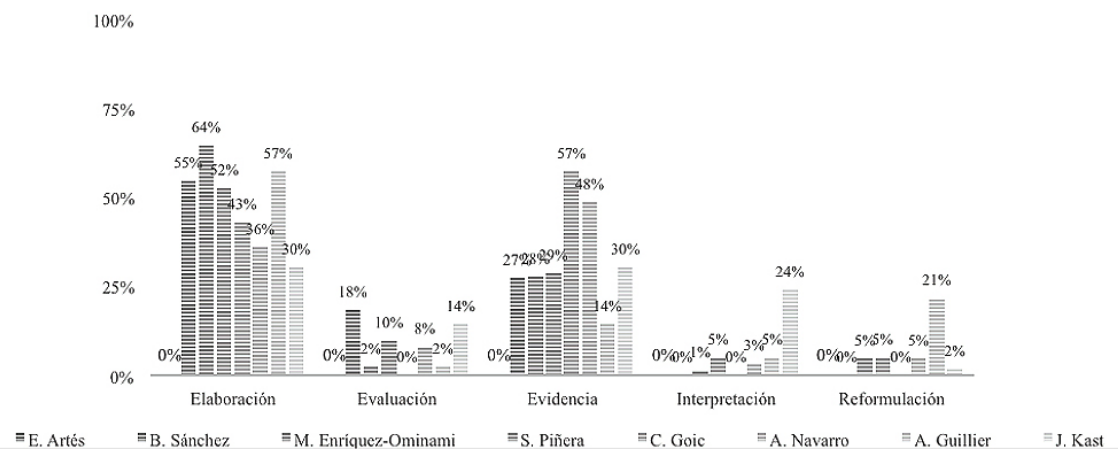

Gráf. 6. Relaciones intersemióticas de los 8 candidatos presidenciales.

Las relaciones de interpretación y evidencia parecieran provocar la acción de los seguidos a través de retweet, comentario o botón Me gusta. En el caso de la relación de evidencia implica considerar la necesidad de persuadir al lector respecto de un punto de vista a través de diversos recursos como puede ser una fotografía, un gráfico, etc. En cuanto a la Interpretación, es una de las relaciones con mayor grado de subjetividad (KERBRATORICHIONI, 1993), por lo general, realiza el candidato un juicio a un determinado tema o evento, lo que tiene un impacto en el seguidor y eventualmente genera una acción.

Respecto de la relación de interpretación, de acuerdo a la RST, se trata de un vínculo entre el núcleo y el satélite en que el primero presenta una situación y el satélite explica en algún sentido dicha situación, agregando además información adicional al respecto desde un punto de vista subjetivo.

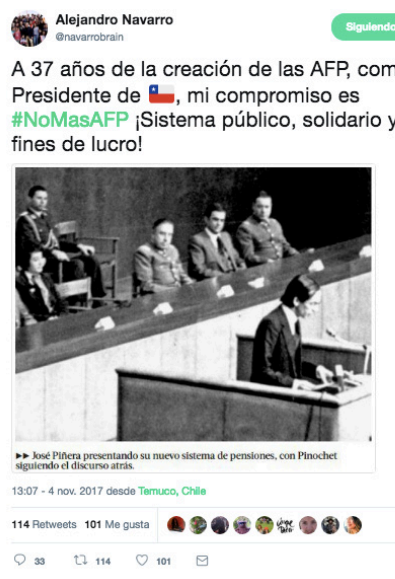

Fig. 3. Tweet del candidato Alejandro Navarro 
Tal como se aprecia en la Figura 3, aquí el núcleo de la relación intersemiótica está dado por la fotografía histórica que utiliza el candidato Alejandro Navarro en la que aparece José Piñera, hermano del actual presidente de Chile, Piñera, presentando el sistema de pensiones que actualmente rige a Chile ante el Dictador Augusto Pinochet en la década del 80. En el satélite, es decir, las palabras del tweet, el candidato Alejandro Navarro realiza una interpretación de la creación del actual modelo de Administradoras de Fondos de Pensiones (AFP) y señala que él quiere cambiar dicho sistema hacia un modelo "público, solidario y sin fines de lucro" y, por tanto, plantea que dicha fotografía representa el inicio de una propuesta que perjudicó al pueblo chileno.

Ahora bien, en la Figura 4 se puede observar un ejemplo de relación intersemiótica de evidencia.

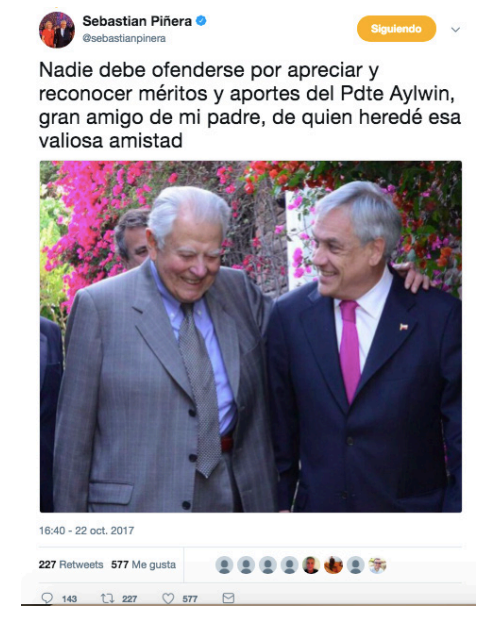

Fig. 4. Tweet emitido por el candidato Sebastián Piñera

Aquí el candidato Piñera, tras haber recibido críticas y cuestionamientos por incluir en la franja oficial la imagen del ex Presidente y líder de la Democracia Cristiana chilena, Patricio Aylwin, propone a través de su tweet las bases de su relación con el líder político chileno. En este caso, tanto las palabras que utiliza, como la imagen elegida, dan cuenta que efectivamente el candidato estuvo muy cerca observando el liderazgo de la Democracia Cristiana de Chile. La fotografía con la imagen de la mano apoyada en el hombro de Piñera no es escogida al azar, da cuenta de la cercanía de ambos, al menos desde la perspectiva del candidato Piñera.

\section{Conclusiones}

En relación al objetivo perseguido por este trabajo, se puede señalar que una de las prácticas discursivas que hasta el momento no han sido analizadas de manera abundante 
es el uso del Twitter con una perspectiva multimodal ligada al análisis del discurso y, por tanto, este estudio aporta en esa línea.

De acuerdo a los hallazgos, se pueden sostener tres ideas centrales. En primer lugar, de manera general que los candidatos hacen un uso más bien unidireccional de la comunicación, y no potencian la interacción con quienes los siguen en Twitter. Esto se ve reflejado por el tipo de relación intersemiótica que utilizan los candidatos en que prima la elaboración en la cual se aporta información, pero no se realiza una interpretación o evaluación, relaciones que buscan apelar a la audiencia.

En segundo lugar, existe una correspondencia entre la tasa de engagement y el tipo de relación intersemiótica que se utiliza por los candidatos. Esto se ve reflejado de la siguiente forma: a mayor tasa de engagement, el tipo de relación intersemiótica se centra en interpretación y evaluación, por lo tanto, pareciera que los candidatos son conscientes de la manera en que se construye significados en un tweet y cómo su visión respecto de un tema puede potenciar de manera significativa en la tasa de interacciones. Sin embargo, solo ocurre en algunos candidatos y no en todos.

En tercer lugar, se refleja un sub-uso de la herramienta Twitter sólo como una caja de resonancia por parte de los candidatos, ya que lo que hacen principalmente a través de sus tweets es informar acerca de sus actividades en diversas instancias sociales, sea medio, sea conferencia u otro similar. De acuerdo a lo visto, los candidatos no comprenden las potencialidades de este medio, sobretodo en lo que se refiere a la forma de interacción que ofrece Twitter (JERVIS, 2015).

En cuanto a las limitaciones se observaron dificultades en la establecimiento del corpus en Twitter. La interacción casi instantánea que posibilita esta nueva herramienta de comunicación hace que su demarcación sea compleja. ¿Cómo delimitar los tweets a considerar? ¿Se deben contemplar sólo los tweets del usuario o los retweets también deben ser incluidos? Preguntas como estas son difíciles de resolver, pero resultan ser necesarias para objetivo y análisis que se buscan en una investigación. Esto implica que el desafío de futuras análisis en esta nueva práctica discursiva requiere contar principalmente con herramientas metodológicas adecuadas para el examen, en este caso, de la interacción a través de Twitter y su uso como herramienta de estrategia política, no solo por medio de las palabras sino también en conjunto con las imágenes que se presentan en los tweets.

Liliana Cecilia Vásquez-Rocca es docente de la Dirección de Formación General, Facultad de Educación y Ciencias Sociales, sede Viña del Mar, de la Universidad Andrés Bello. Doctora en Lingüística por la Pontificia Universidad Católica de Valparaíso (PUCV) y Periodista por la misma Casa de Estudios.

liliana.vasquez@unab.cl 


\section{Referencias:}

ALONSO-MUÑOZ, L.; MIQUEL-SEGARRA, S.; CASERO-RIPOLLÉS, C. Un potencial comunicativo desaprovechado. Twitter como mecanismo generador de diálogo en campaña electoral. Obra Digital, 11, p. 39-58, 2016.

ARELLANO, R.; FERNÁNDEZ, M. A. Primarias Presidenciales. Un análisis electoral y político. Análisis, Documento № 19, Julio 2017. Disponible en: <http://host-201-221-123-195.ip.udd.cl/ bitstream/handle/11447/1596/An\%C3\%A1lisis\%2019-Arellano-Primarias-Presidenciales-V.F.-1. pdf? sequence=1>. Acceso en: 17 mayo 2019.

BARBERÁ, P.; RIVERO, G. Understandig the political representativeness of Twitter users. Social Science Computer Review, 33, 6, 12, p. 712-729, 2014.

BARTHES, R. Lo obvio y lo obtuso. Imágenes, gestos y voces. Madrid: Paidós, 2014.

CALDEVILLA DOMíNGUEZ, D. Democracia 2.0: la política se introduce en las redes sociales. Pensar la Publicidad, III, 2, p. 31-48, 2009.

CALVO-RUBIO, L.M. El uso de Twitter por los partidos políticos durante la campaña del 20D, Sphera Publica, 1 (17), p. 111-131, 2017.

CHADWICK, A. The Hybrid Media System: Politics and Power. Oxford: Oxford University Press, 2013.

CHILE. Ley № 18.700, de 19 de abril de 1988. Ley orgánica constitucional sobre votaciones populares y escrutinios. Biblioteca del Congresso Nacional de Chile: Legislación chilena, Ministério del Interior, 1988. Disponible en: <http://bcn.cl/1v16w>. Acceso en: 17 mayo 2019.

. Ley $N^{\circ} 19.884$, de 7 de julio de 2003. Sobre transparencia, limite y control del gasto electoral. Biblioteca del Congresso Nacional de Chile: Legislación chilena, Ministério del Interior; Subsecretaria del Interior, 2003. Disponible en: <http://bcn.cl/1v3jl>. Acceso en: 17 mayo 2019.

CONGOSTO, M.; FERNÁNDEZ, M.; MORO, E. Twitter y política: información, opinión y ¿ predicción?. Cuadernos de comunicación Evoca, 4, p. 11-16, 2011.

CRESSWELL, J. Research design. Qualitative and quantitative approaches. Thousand Oaks: Sage, 1994.

GOLBECK, J., GRIMES, J.M.; ROGERS, A. Twitter use by the U.S. Congress. Journal of the American Society for Information Science and Technology, 61(8), p. 1612-1621, 2010.

GRANT, W.J., MOON, B; GRANT, J.B. Digital Dialogue? Australian Politicians' use of the Social Network Tool Twitter. Australian Journal of Political Science, 45(4), p. 579-604, 2010.

HERNÁNDEZ, R., FERNÁNDEZ, C.; BAPTISTA, P. Metodología de la investigación. México: McGraw-Hill, 2010.

HODGE, R.; KRESS, G. Social Semiotics. Cambridge: Polity, 1988.

HONEYCUTT, C; HERRING, S. Beyond Microblogging: Conversation and Collaboration in Twitter. HICSS '09 Proceedings of the 42nd Hawaii International Conference on System Sciences. Washington: IEEE Computer Society, p. 1-10, 2009.

JERVIS, J. El fin de los medios de comunicación de masas. ¿Cómo serán las noticias del futuro? Barcelona: Gestión 2000, 2015.

JOVANOVIC, D.; VAN LEEUWEN, T. Multimodal dialogue on social media. Social Semiotics, 28:5, p. 683-699, 2018.

JUNGHERR, A. Four Functions of Digital Tools in Election Campaigns: The German Case. The International Journal of Press/Politics, 21(3), p. 358-377, 2016. Disponible en: <https://doi. org/10.1177/1940161216642597>. Acceso en: 17 mayo 2019. 
KERBRAT-ORECCHIONI, C. La enunciación. De la subjetividad en el lenguaje. Buenos Aires: Edicial, 1993.

KRESS, G.; VAN LEEUWEN, T. Multimodal Discourse - The Modes and Media of Contemporary Communication. London: Arnold, 2001.

KRESS, G. El alfabetismo en la era de los nuevos medios de comunicación. Granada: Editorial Aljibe, 2005.

LANDIS, J.; KOCK, G. The measurement of observeragreement for categorical data. Biometrics, 33, p. $159-74,1977$.

LIU, Y; O'HALLORAN, K. Intersemiotic Texture: Analyzing cohesive devices between language and images. Social Semiotics, 19(4), p. 367-388, 2009.

MANCERA RUEDA, A. Cortesía en 140 caracteres: Interacciones en Twitter entre periodistas y prosumidores. Revista de Filología, 32, p. 163-180, 2014.

MANN, W.; TABOADA, M. RST Web Site, 2010. Disponible en: <http://www.sfu.ca/rst/>. Acceso en: 17 mayo 2019.

MANN, W.; THOMPSON, S. Rhetorical Structure Theory: Toward a functional theory of text organization. Text, 8(3), p. 243-281, 1988.

NEWMAN, N. et al. Reuters Institute Digital News Report 2017. Oxford: Reuters Institute for the Study of Journalism; University of Oxford, 2017. Disponible en: <https://reutersinstitute.politics.ox.ac.uk/sites/ default/files/Digital\%20News\%20Report\%202017\%20web_0.pdf?utm_source=digitalnewsreport. org\&utm_medium=referral>. Acceso en: 17 mayo 2019.

ORIHUELA, J.L. Mundo Twitter. Barcelona: Alienta, 2011.

80 claves sobre el futuro del periodismo. Madrid: Anaya Multimedia, 2012.

PINGDOM Royal. Report: Social network demographics in 2017. 2017. Disponible en: <https:// royal.pingdom.com/2017/05/10/social-media-in-2017/>. Acceso en: 17 mayo 2019.

RAMONET, I. La explosión del periodismo. Buenos Aires: Capital Intelectual, 2011.

RODRÍGUEZ ANDRÉS, R.; UREÑA UCEDA, D. Diez razones para el uso de Twitter como herramienta en la comunicación política y electoral. Comunicación y pluralismo, 10, p. 89-106, 2011.

SOLA-MORALES, S.; RIVERA GALLARDO, R. El tratamiento periodístico sobre la corrupción política. Análisis comparado del caso SQM en Chile y del caso de Bárcenas en España. Estudios sobre el Mensaje Periodístico, 23 (1), p. 647-662, 2017.

STROMER-GAlLEY, J. Presidential Campaigning in the Internet Age. Oxford: Oxford University Press, 2014.

SURAY, A. Argumentación y discurso político en Twitter. Análisis de la campaña presidencial argentina 2011. Aposta. Revista de Ciencias Sociales, 69, p. 39-66, 2016. Disponible en: <http://apostadigital. com/revistav3/hemeroteca/asuray1.pdf>. Acceso en: 17 mayo 2019.

TABOADA, M.; MANN, W. Applications of Rhetorical Structure Theory. Discourse studies, 8(4), p. 567-588, 2006.

TABOADA, M.; HABEL, C. Rhetorical relations in multimodal documents. Discourse studies, 15(1), p. 65-89, 2013. 
TWITTER Audit Report. Informe estadístico del perfil @sebastianpinera generado en 03 oct. 2017. Disponible en: <https://www.twitteraudit.com/sebastianpinera>. Acceso en: 17 mayo 2019.

ZAPPAVIGNA, M. Ambient affiliation: a linguistic perspective on Twitter. New Media Society, 13 (5), p. 788-806, 2011.

Artigo recebido em 01/12/2018 e aprovado em 27/03/2019. 